\title{
Role of rat autologous skin fibroblasts and mechanism underlying the repair of depressed scars
}

\author{
JUAN ZHAO $^{1}$, YAN-CHUN LIU ${ }^{1}$, YAN-HUA SHI ${ }^{1}$, YA-QIN XIE ${ }^{1}$, HAI-PENG CUI ${ }^{1}$, \\ YING LI ${ }^{1}$, XIANG-JUN LI ${ }^{2}$ and LI-QUN REN ${ }^{2}$ \\ ${ }^{1}$ Department of Pathophysiology, Chengde Medical College, Chengde, Hebei 067000; \\ ${ }^{2}$ Department of Experimental Pharmacology and Toxicology, Medical School of Jilin University, \\ Changchun, Jilin 130021, P.R. China
}

Received March 14, 2015; Accepted May 4, 2016

DOI: $10.3892 /$ etm.2016.3442

\begin{abstract}
The aim of the present study was to provide reliable experimental evidence for the application of autologous skin fibroblasts (asFbs) in the repair of depressed scars. In the experiments, depressed trauma was induced in male Wistar rats, and fibroblasts were separated from the removed skin tissues to culture in medium. In vitro cultured asFbs were injected into the depressed scar sites of rats, and the repair function of asFbs in the depressed scars was then examined at the cellular and whole-animal levels. The expression levels of type I and type III collagen in the dermal layer of the skin injected with asFb cells were significantly higher, as compared with those of the control, and type I collagen expression was significantly higher compared with Type III. Re-injection of asFbs into the dermal layer of depressed scars can markedly improve their repair. These results may prove useful for skin repair in clinical settings.
\end{abstract}

\section{Introduction}

Fibroblasts (Fbs) are present in the dermal layer of the skin and are the primary dermal cells to produce collagen and other extracellular matrix (ECM) components, and their normal proliferation and differentiation maintain the structure and physiological function of the skin $(1,2)$. Depressed scars are characterized by a change in the structure of the dermal skin layer, as well as a reduced number of Fbs $(3,4)$. Surgery, trauma, infections or other causes can make defects in the dermis layer of the skin and subcutaneous tissues, and to deplete the ECM forming a permanent depressed scar (5-7). These scars distress patients and push towards applying

Correspondence to: Professor Li-Qun Ren, Department of Experimental Pharmacology and Toxicology, Medical School of Jilin University, 1163 Xinmin Street, Changchun, Jilin 130021, P.R. China

E-mail: yangxhjlu@sina.com

Key words: skin, fibroblasts, collagen, depressed scar medical cosmetics. ECM is significant in the process of skin repair. It bridges intercellular signal transduction, connection, and physiological processes, of which Type I and III collagens (in particular type I collagen) is predominantly associated with the repair of depressed scars $(8,9)$. Fbs are significant repair cells for wound healing that generate a large number of tissue healing factors as the skin is damaged (10-12). Their abilities to produce collagens may lead to accelerated wound healing and improved scar repair $(1,2,9)$. In the present study, autologous skin Fbs (asFbs) were cultured in vitro using a depressed trauma rat model. The function of asFbs in the repair of depressed scars was examined at the whole-animal and cellular levels, in order to provide a reliable scientific basis for the use of asFbs in medical cosmetology.

\section{Materials and methods}

Reagents. RPMI-1640 medium and type IV collagenase were purchased from Gibco (Thermo Fisher Scientific, Inc., Waltham, MA, USA); rabbit anti-rat type I collagen polyclonal antibody (BA0325) and rabbit anti-rat type III collagen polyclonal antibody (BA0326) and mouse anti-rat vimentin monoclanal antibody (BM0135), biotinylated rabbit anti-goat secondary antibody IgG (BA1003) and biotinylated goat anti-mouse secondary antibody IgG (BA1001) were purchased from Wuhan Boster Biological Technology, Ltd. (Wuhan, China); the hydroxyproline (HYP) kit, S-ABC immunohistochemistry kit and DAB color kit were purchased from Fuzhou Maixin Biotech Co., Ltd. (Fuzhou, China).

Animals and construction of a depressed trauma model. A total of 20 male Wistar rats weighing 250-300 g were provided by the Animal Department of the Bethune Medicine Division of Jilin University (Changchun, China). They were fed in $25^{\circ} \mathrm{C}, 12: 12 /$ light:dark cycle, and allowed free access to food and water. As previously described by Ren et al (2), a surgical method was used to establish a rat model of depressed trauma. The surgical procedure was conducted as follows: The rats were fixed in a dorsal position prior to hair removal. The rats were under anesthesia with $10 \mathrm{wt} . \%$ chloral hydrate $(3 \mathrm{ml} / \mathrm{kg}$; Tianjin Fuchen Chemical Reagent Factory, Tianjin, China). Conventional surgical sterilization 
was performed with $20 \%$ iodine and $75 \%$ ethanol. A skin and deep muscular layer of $\sim 3 \times 3 \mathrm{~cm}$ was removed on either side of the spine. The surface of the wounds were then sutured to cause depressed scars. Following creation of the wound, each rat was fed separately and the wound was carefully monitored in order to prevent infection. The rats were observed daily to determine their systemic reactions and wound healing. The excised skin was used for the in vitro culture of asFbs. Animal experiments in the present study was approved by the Animal Ethics Committee of Jilin University ad the experiments were performed in the College of Pharmacy at the University.

Isolation and culture of asFbs. Following removal from the rats, the skin was soaked in $75 \%$ ethanol for $1 \mathrm{~min}$, placed in a sterile petridish, rinsed with phosphate-buffered saline (PBS), and cut into $5 \times 5 \mathrm{~mm}$ sections using a pair of sterile scissors. The tissue sections were then digested with $0.25 \%$ trypsin and incubated overnight at $4^{\circ} \mathrm{C}$. The following day, sterile ophthalmic scissors and tweezers were used to gently remove the epidermis, subcutaneous muscle and adipose tissues, retaining the dermis. The skin tissue samples were sectioned and digested with $0.25 \%$ type IV collagenase at $37^{\circ} \mathrm{C}$ for $4 \mathrm{~h}$. Following filtering with 200 -mesh sieves and centrifugation at $1,000 \mathrm{rpm}$ at room temperature for $15 \mathrm{~min}$, the supernatant was removed. RPMI-1640 medium supplemented with $10 \%$ fetal bovine serum (Gibco; Thermo Fisher Scientific, Inc.,) was added to form a cell suspension. The cells were counted and inoculated into $25 \mathrm{ml}$ culture flasks at a density of $1 \times 10^{4}$ cells $/ \mathrm{ml}$, then placed in $\mathrm{CO}_{2}$ incubator with $37^{\circ} \mathrm{C}, 5 \% \mathrm{CO}_{2}$ and $90 \%$ humidity. After 3 days of static culture, the cells were observed under an inverted microscope, and then the medium was refreshed every other day.

Reinjection of asFbs. When the cultured cells had proliferated to the third generation and reached $90 \%$ confluence ( 21 days following found creation), the cells were digested with $0.25 \%$ trypsin and suspended in $1 \mathrm{ml}$ PBS to form a density of $1 \times 10^{7}$ cells $/ \mathrm{ml}$. The cells were then injected into the scar dermis of the left side of the rats (cell injection side). The right dermal scar served as a control (scar control side). The changes in the scar following cell injection were observed by eye at 7 and 30 days. Finally, the rats were sacrificed and the skin from the experimental sites of the rats was removed for histological examination.

Morphological observation and identification. Cells were digested with $0.25 \%$ trypsin and prepared for cell suspension, adjusting the cell density to $\sim 1 \times 10^{4} / \mathrm{ml}$. The cells were then seeded onto 24 -well plates, containing pre-placed sterilized coverslips at the bottom to allow cells to adhere. When the cells grew to a monolayer, they were washed three times with PBS and fixed with $95 \%$ ethanol for $30 \mathrm{~min}$. Conventional hematoxylin and eosin (H\&E) staining was performed in order to observe cell morphology under an optical microscope.

The cells were identified with an immunohistochemical $\mathrm{S}-\mathrm{ABC}$ staining method using mouse anti-rat vimentin monoclonal antibodies (dilution, 1:100) incubated at room temperature overnight and biotinylated rabbit anti-mouse secondary antibody IgG (dilution, 1:500) incubated at $37^{\circ} \mathrm{C}$ for $2 \mathrm{~h}(13,14)$. DAB substrate liquid was used for staining at room temperature for $\sim 5 \mathrm{~min}$. An optical microscope was used at x100 to count the number of positively-stained cells, and the percentage of positive cells was calculated.

AsFb viability and growth curve. The 3-10 passaged cells were digested $0.25 \%$ trypsin to form a single cell suspension with a density of $1 \times 10^{6} / \mathrm{ml}$. Trypan blue staining was used to test cell viability (15). The cells were then counted and inoculated in 96-well plates at a final concentration of $1 \times 10^{3} / \mathrm{ml}$. The growth curves were measured by MTT assay (16).

Cell morphology at the cell injection sites. H\&E staining was routinely conducted as follows: The cells were fixed with formalin, embedded in paraffin, cut into $4 \mu \mathrm{m}$ sections, dewaxed in xylene, dehydrated with gradient ethanol and stained with H\&E (17).

Immunohistochemistry staining of type I and type III collagens at the cell injection site. The S-ABC method was used for immunohistochemical staining according to the manufacturer's instructions in the S-ABC immunohistochemistry kit (Fuzhou Maixin Biotech Co., Ltd.). Briefly, goat anti-rat type I collagen and type III collagen polyclonal antibodies were used at a 1:100 dilution at $37^{\circ} \mathrm{C}$ for $4 \mathrm{~h}$. Biotinylated rabbit anti-goat secondary $\mathrm{IgG}$ was used at a 1:500 dilution at $37^{\circ} \mathrm{C}$ for $2 \mathrm{~h}$. S-ABC reagents were used following the manufacturer's instructions (Wuhan Boster Biological Technology, Ltd.). Freshly prepared DAB substrate solution was used at room temperature for $\sim 3-5$ min for staining. The collagen-positive area was examined by observing 5 randomly-selected dermal layer specimens from each rat under 5 randomly-selected fields using a microscope (magnification, x400; Eclipse TE-2000-U, Nikon, Tokyo, Japan) equipped with an attached SXM1200F digital camera from the dermal layer of skin for each specimen. Morphological image analysis software Image-Pro ${ }^{\circledR}$ Plus version 6.0. (Media Cybernetics, Inc., Rockville, MD, USA) was used to discriminate between areas of collagen and non-collagen by grayscale and to calculate the percentage of collagen-positive areas.

Statistical analysis. Data were analyzed using the SPSS 11.5 software package (SPSS, Inc., Chicago, IL, USA). The growth curve of the asFbs, the results of the HYP content measurement and the collagen data were presented as means \pm standard deviation. Comparison between groups was performed using one-way analysis of variance. $\mathrm{P}<0.05$ was considered to indicate a statistically significant difference.

\section{Results}

Morphological observation and identification. A total of $4 \mathrm{~h}$ after inoculation, rat asFbs became adherent, long and filamentous, and grew rapidly. The proliferated cells were confluent after 2-3 days, then the cells were closely packed with a whirlpool, radial or palisade arrangement (Fig. 1A).

The third generation of cultured asFb cells was stained using H\&E and observed under light microscopy. The cells were polygonal or long and filamentous with large nuclei, the cell cytoplasm was stained pink, and the nuclei were stained blue and purple as shown in Fig. 1B. The S-ABC method was 


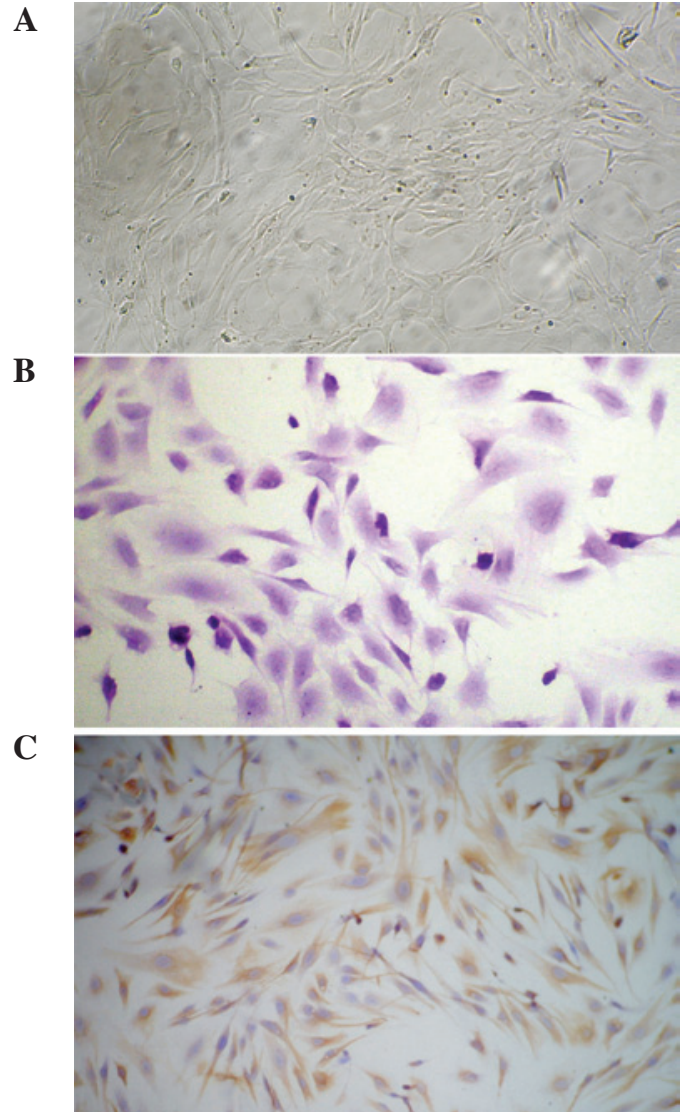

Figure 1. Cell morphology. (A) Rat skin fibroblasts 3 days following cell seeding (magnification, x100). (B) Skin fibroblasts (3rd passage; hematoxylin and eosin staining; magnification, x200). (C) Vimentin immunohistochemistry of the skin fibroblasts (3rd passage; S-ABC assay; magnification, $x 100$ ).

used to stain the vimentin of cultured skin asFbs. The results showed a brown granular cytoplasmic reaction with uncolored nuclei, and $>98 \%$ of the cells were positively stained. The cells expressing vimentin were asFbs, as shown in Fig. 1C.

Skin asFb vitality and growth curve. In the present study, trypan blue exclusion was performed 3 times prior to observation under an inverted microscope. The results demonstrated that few cells were stained blue and the majority of cells resisted staining. After the asFb cells were seeded into 96-well plates at $1 \times 10^{3}$ cells/well, we found that cells increased in the amount within 5 days and grew well. Cell proliferation at days 3-7 was significantly increased compared with day 0 $(\mathrm{P}<0.01)$. The incubation period, logarithmic growth phase, and plateau phase were on days $0-1$, days $1-5$ and days 5-7, respectively (Fig. 2A).

Skin asFb recovery following cryopreservation. Following asFb recovery, energy detection was conducted. All cells recovered in good condition with a survival rate of $\sim 85 \%$. The growth curves prior to and following recovery were similar, suggesting the biological characteristics of asFbs were stable (Fig. 2B). These results suggest that cells can be successfully cryopreserved and recovered.

Determination of the HYP content in the culture medium of skin asFbs. The HYP kit demonstrated that HYP levels
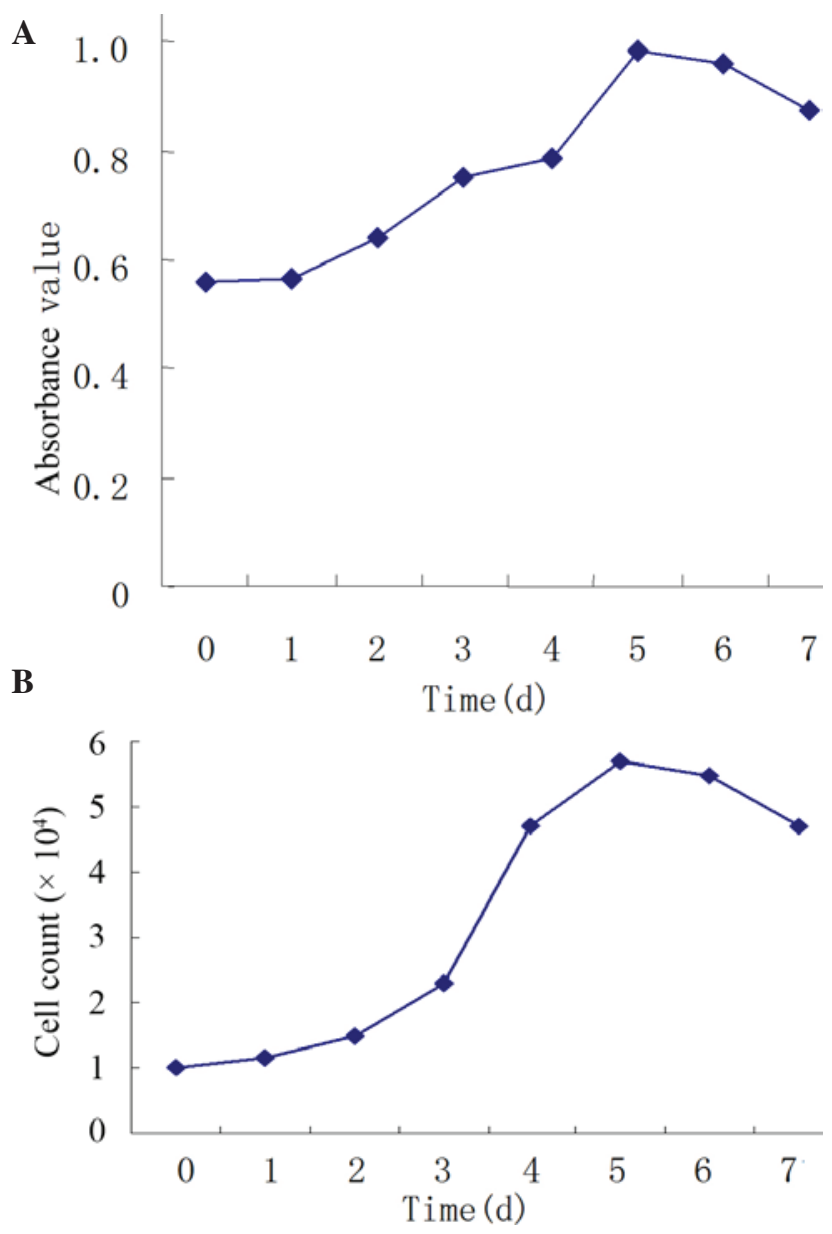

Figure 2. Growth curves of skin fibroblasts (A) prior to cryopreservation and (B) following recovery.

increased with the proliferation of cells in the culture medium at 3-5 days, and the HYP levels at days 3-6 significantly increased compared with day $1(\mathrm{P}<0.01$; Table I).

Observation of the repair of the depressed scars. After $3 \mathrm{~h}$ of modeling, the bleeding at the wounds of the rats stopped. At 3 days, the wounds were dry and had formed a scab; the sunken scars on the backs of the rats had formed after 10 days, manifesting as linear scars, with lower than normal skin. Prior to reinjection, the scars exhibited no significant difference on either side. A total of 7 days after reinjection, the scar sites injected with asFBs were significantly lighter compared with the control side; the scar color had faded and the sunken appearance of the scars were improved compared with the control skin. A total of 30 days after reinjection, the scars sites further improved and the scars disappeared at the injected sites, with a similar color and height as the normal control skin (Fig. 3).

Morphological observation. H\&E staining demonstrated that in the dermal layer of the scar skin on the control side, the cells appeared in a spindle shape with pale blue nuclei and pink cytoplasm. A total of 7 days after cell injection, the number of cells in the dermal layer of the skin on the cell injection side increased significantly compared with the control side. A total of 30 days following cell injection, the number of cells in the dermal 
Table I. Levels of hydroxyproline in the culture supernatants of skin fibroblasts.

\begin{tabular}{lc}
\hline Time (days) & HYP $(\mathrm{mg} / \mathrm{l})$ \\
\hline 1 & $3.85 \pm 0.16$ \\
2 & $5.13 \pm 0.08$ \\
3 & $9.40 \pm 0.09^{\mathrm{b}}$ \\
4 & $13.99 \pm 0.30^{\mathrm{b}}$ \\
5 & $18.00 \pm 0.23^{\mathrm{b}}$ \\
6 & $7.38 \pm 0.47^{\mathrm{a}}$ \\
7 & $3.63 \pm 1.72^{\mathrm{a}}$
\end{tabular}

Data are presented as means \pm standard deviation $(\mathrm{n}=6) .{ }^{\mathrm{a}} \mathrm{P}<0.05$ and ${ }^{\mathrm{b}} \mathrm{P}<0.01$, vs. 1 day. HYP, hydroxyproline.

A

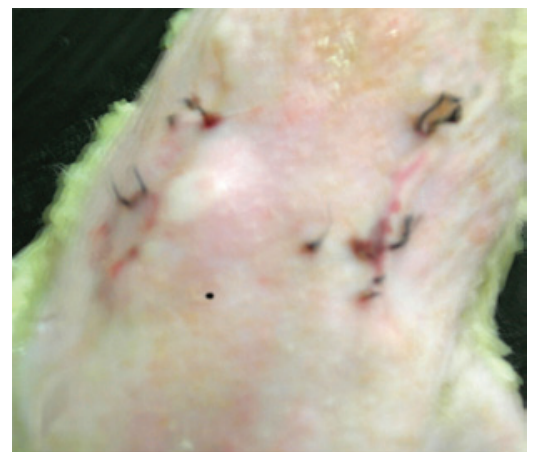

B

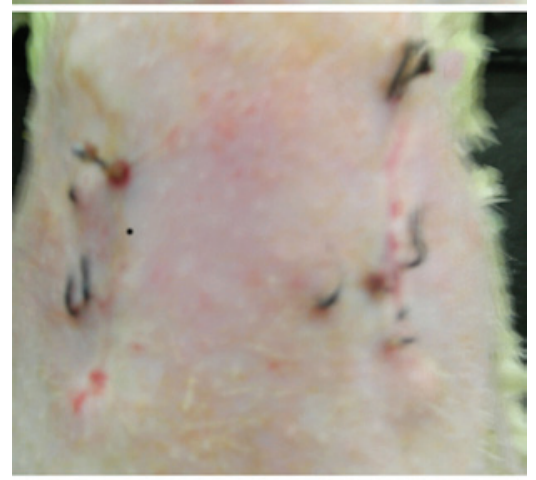

C

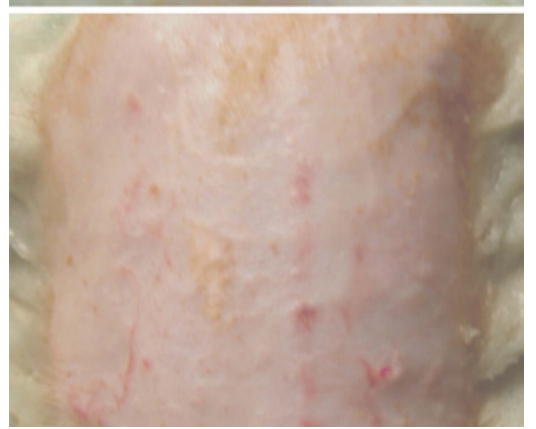

Figure 3. Repair of depressed scars. (A) Rats on the day of cell injection. Cells were injected into the left side of the back, the right side acted as a control (no cell injection). (B) Scar condition 7 days following cell injection. The wound on the left side recovered faster than the right side. (C) Scar condition 30 days following cell injection. The scar on the left side healed in 30 days, but the one on the right did not.

skin layer on both the cell injection and control side increased compared with the number of cells counted on day 7 (Fig. 4).

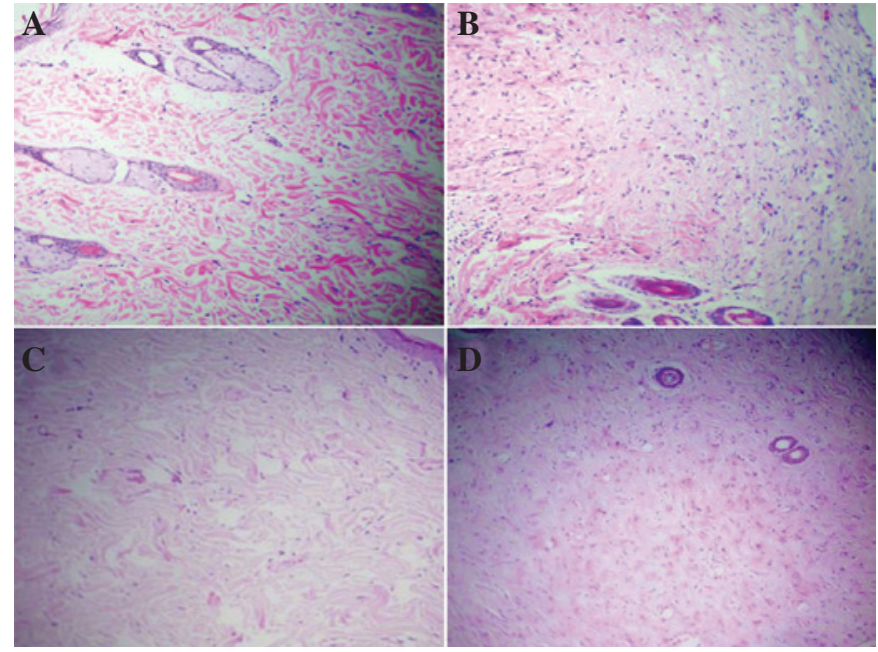

Figure 4. Comparative observation of cell numbers in the dermal layer of the skin, as determined by hematoxylin and eosin staining (magnification, x100). (A) Scar control side 7 days following cell injection. (B) Cell injection side 7 days following cell injection. (C) Scar control side 30 days following cell injection. (D) Cell injection side 30 days following cell injection. The cell count on the side where the cell injection was done was markedly larger compared to the control side after 7 and 30 days.

Immunohistochemistry of type I and type III collagens. For type I and type III collagen staining, the collagen fibers were positive and showed a brown color, the asFbs in the dermis layer were also positive to be cytoplasmic brown substance around the nucleus, but the nucleus was not colored. Immunohistochemical observation of type I collagen staining demonstrated that the percentage of collagen type I-positive areas in all the groups were statistically significant $(\mathrm{P}<0.01$; Table II). A total of 7 days after cell injection, the positive staining of collagen on the scar control side was lower compared with the cell injection side. A total of 30 days after injection, the number of asFbs and the collagen staining in both the cell-injected and the control scar were higher compared with those at 7 days. The immunohistochemical staining of Type III collagen and type I collagen demonstrated similar results, namely that 30 days after injection, the collagen staining and the number of cells in the dermal layer were increased compared with those at 7 days, and their collagen area fractions were statistically significant $(\mathrm{P}<0.01$; Table II). Although after cell injection the number of asFbs, type I collagen levels and type III collagen levels in the dermal layer were all increased compared with the control side, immunohistochemical staining demonstrated that the amount of type I collagen increased significantly more compared with type III collagen. These results are shown in Table II and Fig. 5.

\section{Discussion}

With the development of modern society and the improvement of living standards, an increased emphasis is placed on quality of life. As an important part of medical cosmetics, trauma repair using beauty treatments has become increasingly popular (18-21). Depressed scars, resulting from surgery, trauma, infections or other causes, lead to defects in the dermis layer of the skin and subcutaneous tissues, which are depleted of collagen and elastin in the subsequent healing process, 
Table II. Type I and type III collagen-positive areas at various time points (\%).

\begin{tabular}{lccrl}
\hline Group & $\begin{array}{c}\text { Cell injection } \\
\text { time (days) }\end{array}$ & $\begin{array}{c}\text { Number } \\
\text { of animals }\end{array}$ & $\begin{array}{c}\text { Area of type I } \\
\text { collagen (\%) }\end{array}$ & $\begin{array}{c}\text { Area of type III } \\
\text { collagen }(\%)\end{array}$ \\
\hline Cell injection & 7 & 5 & $36.33 \pm 0.41^{\mathrm{a}}$ & $10.06 \pm 0.67^{\mathrm{a}}$ \\
Scar control & 7 & 5 & $23.20 \pm 0.34^{\mathrm{a}}$ & $1.61 \pm 0.28^{\mathrm{a}}$ \\
Cell injection & 30 & 5 & $25.79 \pm 0.20^{\mathrm{a}}$ & $15.84 \pm 0.74^{\mathrm{a}}$ \\
Scar control & 30 & 5 & $9.80 \pm 0.18^{\mathrm{a}}$ & $5.41 \pm 0.47^{\mathrm{a}}$ \\
\hline
\end{tabular}

${ }^{\mathrm{a}} \mathrm{P}<0.01$, statistically significant vs. scar control.
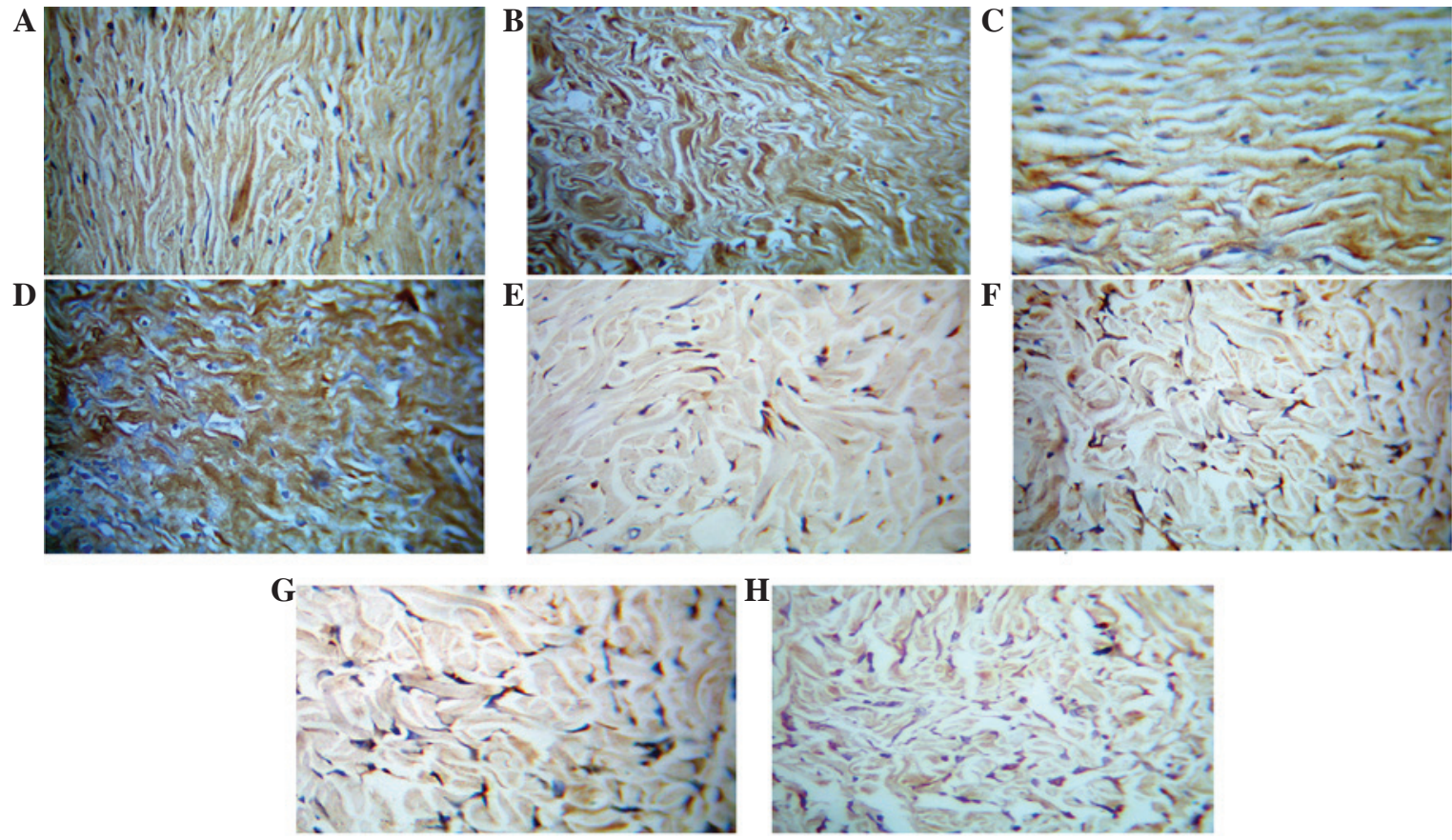

Figure 5. Immunohistochemical analysis of type I and type III collagens (magnification, $\mathrm{x} 400$ ). (A) Type I collagen staining of the scar control side 7 days after injection of asFbs. (B) Type I collagen staining of the cell injection side 7 days after asFb injection. (C) Type I collagen staining of the scar control side 30 days after asFb injection. (D) Type I collagen staining of the cell injection side 30 days after asFb injection. (E) Type III collagen staining of the scar control side 7 days after asFb injection. (F) Type III collagen staining of the cell injection side 7 days after asFb injection. (G) Type III collagen staining of scar control side 30 days after asFb injection. (H) Type III collagen staining of the cell injection side 30 days after asFb injection. asFbs, autologous skin fibroblasts.

forming a permanent depressed scar (5-7). These scars can be distressing for patients.

In the present study, the autologous culture of asFbs and a rat trauma healing model of depressed scars was used to investigate the role of asFbs in depressed scars both at the whole-animal level and cellular level. Depressed scars are characterized by a change in the structure of the dermis layer of the skin, as well as a reduced number of Fbs $(22,23)$. Therefore, in vitro cultivation of asFbs is an indispensable procedure to study the repair of depressed scars. Combined digestion methods using trypsin and collagenase for the in vitro culture of asFbs are effective laboratory methods, and asFbs cell cultures are highly proliferative, easily adaptable and stable (24-27). The successful culture of asFbs has provided a reliable source of cells for the repair of human depressed scars (22).

Under normal circumstances, skin asFbs are in a relatively quiescent state. When the skin is damaged, cells are activated and enter into the proliferative and metabolic state, and generate a large number of tissue healing factors (10-12). asFbs are important repair cells for wound healing, and therefore the study of the biological behavior of asFbs may lead to the acceleration of wound healing and improve the recovery of the scar tissue.

AsFbs are able to synthesize and secrete collagen, elastin, fibronectin and laminin $(1,2,8,9,22,23)$. These ECM proteins not only support and connect cells, but also act as intercellular bridges during signal transduction, thereby participating in the physiological and pathological processes of cells, and collagen is dominant in the ECM $(8,9)$. The present study examined the main indicators of depressed scars and demonstrated that upon re-injection of in vitro proliferated autologous asFbs into the wound dermis of rat depressed scars, the synthesis and secretion of type I and type III collagens increased, with type I collagen being dominant, markedly promoting the repair of depressed scars. 
In conclusion, the cell culture technique may produce a large number of asFbs with the ability to synthesize and secrete skin collagens. When a certain amount of asFbs are re-injected subcutaneously, they can survive, synthesize and secrete large amounts of collagens, thereby achieving the therapeutic effect of filling depressed scars. As they are autologous tissue cells, the disadvantages of immune and allergic reactions are eliminated. The use of asFBs in cosmetic medicine would be a repair method with simple, safe, minimally-invasive and long-lasting advantages, improving the quality of life of patients who elect to remove their depressed scars.

\section{Acknowledgements}

The present study was funded by The First Youth Talent Project and the Key Disciplines Projects of the Hebei Province.

\section{References}

1. Zeng W, Wei ZR, Liu D, Chai M and Zhao YM: Preliminary clinical observations on autologous cultured skin fibroblasts transplantation to treat the facial soft tissue deficiencies. Zhonghua Zheng Xing Wai Ke Za Zhi 29: 29-33, 2013 (In Chinese).

2. Ren HT, Hu H, Li Y, Jiang HF, Hu XL and Han CM: Endostatin inhibits hypertrophic scarring in a rabbit ear model. J Zhejiang Univ Sci B 14: 224-230, 2013.

3. Jung DH, Medikeri GS, Chang GU and Hyun SM: Surgical techniques for the correction of postrhinoplasty depressed scars on the nasal tip. JAMA Facial Plast Surg 17: 405-412, 2015.

4. Seok J, Choi SY, Park KY, Jang JH, Bae JH, Kim BJ, Kim MN and Hong CK: Depressed scar after filler injection successfully treated with pneumatic needleless injector and radiofrequency device. Dermatol Ther 29: 45-47, 2016.

5. Skigen AL, Bedrock RD and Stopperich PS: Correction of the depressed, retracted, post-tracheostomy scar. Plast Reconstr Surg 103: 1703-1705, 1999.

6. Inchingolo F, Tatullo M, Abenavoli FM, Marrelli M, Inchingolo $\mathrm{AD}$, Corelli $\mathrm{R}$, Inchingolo $\mathrm{AM}$ and Dipalma $\mathrm{G}$ : Surgical treatment of depressed scar: A simple technique. Int J Med Sci 8: 377-379, 2011.

7. Khan F, Richards K and Rashid RM: Hyaluronic acid filler for a depressed scar. Dermatol Online J 18: 15, 2012.

8. Kubo K and Kuroyanagi Y: A study of cytokines released from fibroblasts in cultured dermal substitute. Artif Organs 29: 845-849, 2005.

9. Burd A and Chiu T: Allogeneic skin in the treatment of burns. Clin Dermatol 23: 376-387, 2005.

10. Chang H, Chi JT, Dudoit S, Bondre C, van de Rijn M, Botstein D and Brown PO: Diversity, topographic differentiation, and positional memory in human fibroblasts. Proc Natl Acad Sci USA 99: $12877-12882,2002$
11. Clark DP, Hanke CW and Swanson NA: Dermal implants: Safety of products injected for soft tissue augmentation. J Am Aced Dermatol 21: 992-998, 1989.

12. Viyoch J, Buranajaree S, Grandmottet F, Robin S, Binda D, Viennet $\mathrm{C}$, Waranuch $\mathrm{N}$ and Humbert P: Evaluation of the effect of Thai breadfruit's heartwood extract on the biological functions of fibroblasts from wrinkles. J Cosmet Sci 61: 311-324, 2010.

13. Kotaska K, Petrak B, Kukacka J, Kraus J and Prusa R: Anti-vimentin antibodies and neuron-specific enolase in children with neurofibromatosis type-1. Neuro Endocrinol Lett 28: 761-764, 2007.

14. Chen X, Xu R, Jiang YN, Zhu WN and Wang YH: Simultaneous separation of primary cardiomyocytes and cardiac fibroblasts from neonatal rats with density gradient centrifugation. Sheng $\mathrm{Li}$ Xue Bao 67: 423-430, 2015 (In Chinese).

15. Avelar-Freitas BA, Almeida VG, Pinto MC, Mourão FA, Massensini AR, Martins-Filho OA, Rocha-Vieira E and Brito-Melo GE: Trypan blue exclusion assay by flow cytometry. Braz J Med Biol Res 47: 307 -315, 2014.

16. Suto A, Kubota T, Shimoyama Y, Ishibiki K and Abe O: MTT assay with reference to the clinical effect of chemotherapy. J Surg Oncol 42: 28-32, 1989.

17. Werely WA: Automated hematoxylin and eosin staining for large volumes of tissue. Am J Med Technol 42: 285-287, 1976.

18. Cooper JS and Lee BT: Treatment of facial scarring: lasers, filler, and nonoperative techniques. Facial Plast Surg 25: 311-315, 2009.

19. Han HH, Kim SY, Lee YJ, Moon SH and Oh DY: Donor-site closure using absorbable dermal staple for deep inferior epigastric artery perforator flaps: Its efficacy and cosmetic outcomes. Springerplus 23: 363, 2016.

20. Byun SH, Ahn KM, Kim SM and Lee JH: Functional and cosmetic outcome after closure of radial forearm free flap donor defect with porcine collagen membrane. J Craniomaxillofac Surg 44: 527-532, 2016.

21. Tanaydin V,Conings J, Malyar M, van der Hulst R and van der Lei B: The role of topical vitamin $\mathrm{E}$ in scar management: A systematic review. Aesthet Surg J: Mar 14, 2016 (Epub ahead of print) pii: sjw046.

22. Munavalli GS, Smith S, Maslowski JM and Weiss RA: Successful treatment of depressed, distensible acne scars using autologous fibroblasts: A multi-site, prospective, double blind, placebo-controlled clinical trial. Dermatol Surg 39: 1226-1236, 2013.

23. McAnulty RJ: Fibroblasts and myofibroblasts: Their source, function and role in disease. Int J Biochem Cell Biol 39: 666-671, 2007.

24. Pan S, Chen W, Liu X, Xiao J, Wang Y, Liu J, Du Y, Wang Y and Zhang Y: Application of a novel population of multipotent stem cells derived from skin fibroblasts as donor cells in bovine SCNT. PLoS One 10: e0114423, 2015.

25. Doucet YS and Owens DM: Isolation and functional assessment of cutaneous stem cells. Methods Mol Biol 1235: 147-164, 2015.

26. Tondato F, Zeng H, Goodchild T, Ng FS, Chronos N and Peters NS: Autologous dermal fibroblast injections slow atrioventricular conduction and ventricular rate in atrial fibrillation in swine. Circ Arrhythm Electrophysiol 8: 439-446, 2015.

27. Walmsley GG, Maan ZN, Hu MS, Atashroo DA, Whittam AJ, Duscher D, TEvlin R, Marecic O, Lorenz HP, Gurtner GC and Longaker MT: Murine dermal fibroblast isolation by FACS. J Vis Exp 107: e53430, 2016. 